\title{
Wrightia tinctoria (Roxb) R.Br. - An updated Review
}

\author{
S. Lakshmi Devi ${ }^{1} *$ and Madhu.C.Divakar ${ }^{2}$ \\ 1. College of Pharmacy, SRIPMS, 395, Sarojini Naidu Road, Coimbatore - 641 044, Tamilnadu, India. \\ 2. Directorate of Pharmaceutical Affairs and Drug Control, Ministry of Health, Muscat, Oman
}

Article history: Received: 20 December 2013, revised: 12 January 2014, accepted: 10 February 2014, Available online: 3 April 2014

\begin{abstract}
Plan: The present study aims to facilitate an updated phytochemical and pharmacological activity study reports of various researchers pertaining to the plant Wrightia tinctoria.

Preface: Wrightia tinctoria (Roxb.) R. Br (Apocynaceae) is widely distributed in the plains and slopes of Shevaroy hills of Yercaud Town, situated in Salem district, Tamilnadu. Wrightia tinctoria is extensively used in a number of traditional medicines.

Outcome: Chemical constituents isolated from different parts of the plant W. tinctoria and their biological activities reported are summarised in this review.
\end{abstract}

Key words: Wrightia tinctoria. Biological activities, Phytoconstituents

\section{INTRODUCTION}

Wrightia tinctoria (Roxb.) R.Br belonging to family Apocynaceae is commonly known as Vetpala, Indrajava, Mitha - Indrajau (or) Indigo plant. Distributed throughout Rajputana, Central Provinces, Deccan, Konkan, Circars, Western Ghats of Madras Presidency, Ceylon and Burma - Timor ${ }^{1}$. It is a small deciduous tree with scaly bark, elliptic lanceolate leaves, white fragrant flowers, fruits of 2 distinct pendulous follicles $25-50 \mathrm{~cm}$ by $6-8 \mathrm{~mm}$ and seeds are $1-2 \mathrm{~cm}$ long pointed at the apex with a deciduous coma often more than 3-8 cm long at the base.

It is widely used in Ayurvedic system of medicine for its various uses. The seeds are claimed to be useful as anthelmintic, antidiarrhoeal, antidysenteric, astringent, febrifuge, seminal weakness and as an aphrodisiac. The leaves and bark (decoction) are used, as febrifuge, in toothache, stomachic and tonic in bowel complaints. The bark is used as an antidysenteric, especially useful in piles, to treat skin diseases and biliousness in Ayurvedia ${ }^{2}$. 


\section{REVIEW RESULTS}

\subsection{Pharmacognosy}

Preliminary pharmacognostical studies on the leaves of Wrightia tinctoria (Roxb) R.Br by various research groups ${ }^{3,5,6,7,13,31,33}$ throws light upon the Pharmacognostical standards such as ash values, extractive values, phytochemical tests and microscopical characters of leaf powder, phytoconstituents and fluorescence characters. The data generated for the Pharmacognostical evaluation on Wrightia tinctoria leaves may be useful for establishing the standardization protocols. The HPTLC analysis data indicated that the collected Wrightia tinctoria leaves contain $47.6 \mathrm{mg}$ of lupeol/ $g$ of the total methanolic extract ${ }^{3}$.

\subsection{Phytochemistry}

Though a great deal of chemical investigation has been carried out on Wrightia tinctoria, no review on its complete chemical constituents is on record so far. Its constituents can be broadly categorized as steroids, triterpenoids, flavonoids, isoflavone etc.

The seed part of the plant afforded 9-hydroxy-cis-12 otadecenoic acid (isoricinoleic acid), 9hydroxy stearic acid, tri- isoricinoleoyl glycerol, di-isoricinoleoylglycerols, tri-iso ricinoleoylglycerols, arachidic, linoleic, oleic, myristic, palmitic and stearic acid; sterols-14- $\alpha$ methyl zymosterol (I) desmosterol, clerosterol-24-methylene-25 methyl-cholesterol, 24dehydropollinastanol (m.p $145^{\circ}$ - $148^{\circ}$ ), 24-methyl chloesterol; isoflavone-wrightiadione (II), 24methylene cholesterol, 24-ethyl cholesterol and isofucosterol.

Lupeol (III) and Lupenone (IV) triterpenoid were isolated from the leaves. $\alpha$-Amyrin, $\alpha$-amyrin acetate, $\beta$-amyrin, taraxerol, taraxerol acetate and $\beta$-sitosterol were present in leaves. $\beta$-Sitosterol, $\alpha$-amyrin and its acetate, lupeol benzoate, triterpenoids, steroids and saponins were in Bark. The Latex showed the protease - wrightin. Presence of oleanolic acid, ursolic acid, terpene and wrightial (V) were in pods whereas flavonoids- Quercetin (VI) and rutin was found in flowers.

The immature pods showed the presence of cycloartanes cycloartenone and cycloeucalenol along with $\alpha$-amyrin, $\beta$-amyrin, $\beta$-sitosterol, oleanolic acid, ursolic acid and a new terpene - wrightial $^{4-10}$. The woody stem extract revealed the presence of lupeol, Stigmasterol (VII) and Campesterol ${ }^{11}$ (VIII).

Reports $^{12,21,34}$ on the comparative phytochemical and antibacterial activities of bark of Wrightia tinctoria and Wrightia arborea indicate that the bark extracts showed the presence of alkaloids, phenolics, saponins and tannins in both the species. The antibacterial activities of bark of $W$. tinctoria and $W$. arborea in successive different solvent were tested against gram +ve and gram -ve organisms. The chloroform extracts of $W$. arborea showed the broader spectrum of antibacterial activity when compared with W. tinctoria $^{12}$.

Also Rajani and Srivastava reported Wrightia tinctoria R. Br. belongs to family Apocynaceae commonly called as Sweet Indrajao, Pala Indigo Plant, Dyer's Oleander. "Jaundice curative tree" in south India. 
Sweet Indrajao is a small, deciduous tree with a light gray, scaly smooth bark. Native to India and Burma, Wrightia is named after a Scottish physician and botanist William Wright (1740-1827). Sweet Indrajao is called dhudi (Hindi) because of its preservative nature.

The juice of the tender leaves is used efficaciously in jaundice. Crushed fresh leaves when filled in the cavity of decayed tooth relieve toothache. In Siddha system of medicine, it is used for psoriasis and other skin diseases. Oil 777 prepared out of the fresh leaves of the plant has been assigned to analgesic, anti-inflammatory, and anti-pyretic activities and to be effective in the treatment of psoriasis. The plant is reported to contain presence of flavonoid, glycoflavones-iso-orientin, and phenolic acids.

The various chemical constituents isolated from various parts of the plant are reported as 3,4-Secolup-20 (29)-en-3-oic acid, lupeol, stigmasterol and campetosterol, Indigotin, indirubin, tryptanthrin, isatin, anthranillate and rutin Triacontanol, Wrightial, cycloartenone, cycloeucalenol, $\beta$-amyrin, Alpha-Amyrin, and $\beta$-sitosterol, 14 $\alpha$-methylzymosterol. Four uncommon sterols, desmosterol, clerosterol, 24-methylene-25-methylcholesterol, and 24-dehydropollinastanol, were isolated and identified in addition to several more common phytosterols.
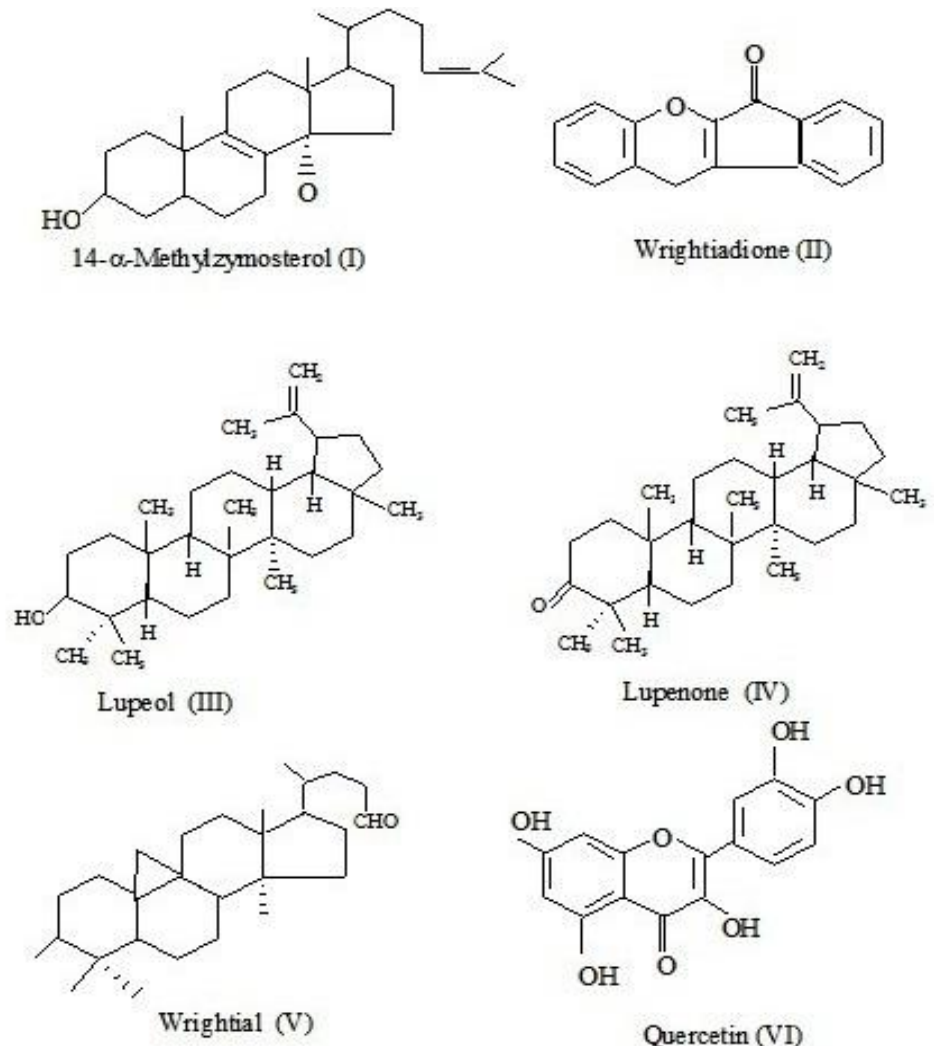<smiles>N#CC(=O)O</smiles>
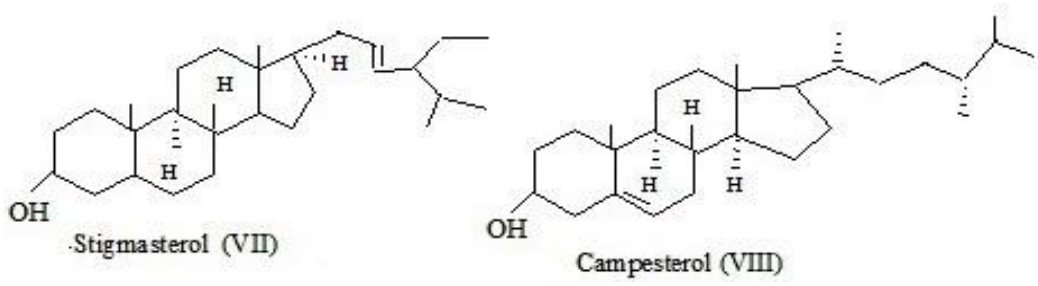
The triterpenoid components of the leaves and pods of Wrightia tinctoria also isolated. This article intends to provide an overview of the chemical constituents present in various parts of the plants and their pharmacological actions and pharmacognostical evaluation ${ }^{13}$.

\subsection{Synthesis of silver nano particles}

In this study the conventional (physical and chemical) method of nano particles synthesis was replaced with biological synthesis of silver nanoparticles by using the leaf extract of Wrightia tinctoria. New drug delivery system has been enhanced with novel techniques like nano particle synthesis and its role in drug delivery system, by exploiting the nanotechnology in particle synthesis. The aqueous extract of Wrightia tinctoria leaves was prepared and mixed with $1 \mathrm{mM}$ AgNO3 solution. After 48 hours the reduction of silver nitrate to silver nanoparticles (AgNPs) was confirmed by UV-visible spectrophotometer.

The size of Silver nanoparticles were characterized by XRD and FTIR and the size were of $19-$ $68 \mathrm{~nm}$. The biosynthesis of AgNPs using Wrightia tinctoria leaf extract is very simple and economic. This green chemistry approach is amenable to large scale commercial production. The use of environmentally benign and renewable plant material offers enormous benefits of ecofriendliness ${ }^{14}$.

\subsection{Pharmacological activity}

\subsubsection{Wound healing activity}

Wound healing activity was evaluated by $70 \%$ ethanolic and methanolic extracts of leaves of Wrightia tinctoria (Roxb.) $\mathrm{R}$. Br (Apocynaceae) using incision and excision wound models on Wistar rats. Wound contraction and period of epithelization where assessed in excision wound model whereas wound tensile strength was determined in case of incision would model. $4 \%$ Wrightia tinctoria methanolic leaf extract phytosome exhibited significant wound healing potential when compared with standard $0.2 \%$ nitrofurazone ointment ${ }^{15}$. Similarly the ethanol extract of bark of Wrightia tinctoria was found to have significant wound healing activity ${ }^{16}$.

\subsubsection{Post coital interceptive activity}

The ethanolic extract of Wrightia tinctoria stem bark and its serial fractions were administered to female rats on days 1-7 or 1-5 postcoitum (Day 1: day of sperm - positive vaginal smear) by the oral route. At autopsy on day 10 postcoitum, the number and status of corpora lutea and implantations were recorded. For estrogen- agonistic activity, immature rats ovariectomized 7 days earlier received the test extract or the vehicle once daily for 3 days and, at autopsy on day 4, uterine weight, status of vaginal opening and extent of vaginal cornification were recorded.

The ethanolic extract of the stem bark of Wrightia tinctoria R.Br. inhibited pregnancy in $100 \%$ of rats when administered orally at a $250 \mathrm{mg} / \mathrm{kg}$ dose on days $1-7$ or $1-5$ postcoitum. On fractionation, the hexane - soluble, chloroform- soluble, water - soluble and water - insoluble fraction showed $100 \%$ anti- implantation effect, while $n$ - butanol- soluble fraction intercepted pregnancy in $75 \%$ of animals when administered in the days 1-5 postcoitum schedule. 
In immature rat bioassay, the active ethanolic extract and its fractions exhibited moderate to potent estrogen - agonistic activity, which might be responsible for their contraceptive action in this species.

Findings demonstrate the antifertility activity of the ethanolic extract of the stem bark of Wrightia tinctoria and its hexane - soluble, chloroform - soluble, water - soluble and water - insoluble fractions. Studies that pursue promising natural products (to identify contraceptive agents from natural sources lacking potent estrogenic activity) towards a fruitful conclusion for development/ lead generation should continue ${ }^{17}$.

\subsubsection{Antinociceptive activity}

The ethyl acetate, acetone and methanol extracts of Wrightia tinctoria bark showed antinociceptive activity on acetic acid - induced writhing test in mice, their effects beings comparable to that of acetyl salicylic acid ${ }^{18}$.

\subsubsection{Parakeratosis}

An experimental histological evaluation on reversal of parakeratosis to ortho-keratosis based on mouse tail test utilises Wrightia tinctoria applied as an emulsion to mouse tail, showed nearly $90 \%$ reversal of parakeratosis to ortho keratosis, a better result when compared with the treatment using retinoid and betamethasone ${ }^{19}$.

\subsubsection{Anti - Pityrosporum oval activity}

Wrightia tinctoria and Hibiscus rosasinensis against the isolates of pityrosporum oval recovered from dandruff. The drug combination exhibited fungicidal activity at a concentration ranging between $500-1000 \mathrm{~g} / \mathrm{ml}^{20}$.

\subsubsection{Anti-dandruff activity}

The antidandruff efficacy of the oil (Dano) prepared from the bark of Hibiscus rosasinensis, Wrightia tinctoria (Indrajau), Cassia alata (Dadmari) and bitter fraction of Azadiracta indica (Neem or Nimba) in Oleum cocos nucifera oil. Microbiological and clinical efficacy of Dano, a Siddha hair oil preparation was studied using in vitro assay, Methylene blue reductase test and reduction of severity of dandruff symptom - scaling post use. The study findings showed that Dano is the best drug of choice for the management of dandruff ${ }^{21}$.

\subsubsection{Anti Psoriasis activity and Antioxidant activity}

The hydro alcoholic extract of Wrightia tinctoria was evaluated for antipsoriatic activity by mouse tail test. It was performed at a dose $200 \mathrm{mg} / \mathrm{kg}$ body weight in mice (25-30g). Isoretinoic acid $(0.5$ $\mathrm{mg} / \mathrm{kg}$ ) was used as the standard. Degree of orthokeratosis, drug activity and the relative epidermal thicknesses were calculated and statistically analyzed. The extract was also evaluated for its antioxidant potential by DPPH, nitric oxide and hydrogen peroxide radical scavenging assays. The extract produced significant $(\mathrm{P}<0.01)$ degree of orthokeratosis compared to control and the drug activity was found to be $70.18 \%$ which is more potent than the standard $(57.43 \%)$. 
The extract showed prominent antioxidant activity in all the assays. The study concludes that the selected plant has antipsoriatic activity and can be used for psoriasis treatment ${ }^{22}$.Similarly Baktha Reddy reported a study on clinical and histopathological evaluation of the effect of Wrightia tinctoria formation on psoriasis vulgaris ${ }^{23}$.

\subsubsection{Clot inducing activity}

A study conducted by Rajesh et al., were compared the clot inducing and is solving properties of Calotropis gigantea R. Br. (Asclepidaceae), Synadenium grantii Hook. F (Euphorbiaceae) latex extracts. All the three latex extracts hydrolyzed casein, fibrinogen and crude fibrin dose dependently.

The proteolytic action on fibrinogen sub unity was in the order of Alpha>Beta>Gama. All extracts exhibited procoagulant activity as assayed by re-calcification time. However, thrombin like activity is restricted to Calotropis gigantea. In addition, the extracts dose - dependently hydrolyzed blood and plasma clots. Furthermore, the hydrolyzing pattern of fibrin in the plasma clot was substantiated by SDS-PAGE. The extracts hydrolyzed all the subunits ( Alpha polymer, alpha chains, gamma - gamma dimer and beta-chain) of fibrin efficiently.

Both fibrinogenolytic and fibrinolytic activity potency of the extracts were in the order of Calotropis gigantea > Synadenium grantii > Wrightia tinctoria. Among the 3 latices, Calotropis gigantea is toxic with a minimum hemorrhagic dose (MHD) of $>75$ microg, whereas Synadenium grantii and Wrightia tinctoria latex extracts were non toxic and did not induce any hemorrhagic effect at the tested dose (>200 microg). The proteolytic activity of Calotropis gigantea latex extract on different substrates was inhibited by IAA. On the other hand the proteolytic activities of Synadenium grantii and Wrightia tinctoria were inhibited by PMSF. Thus the study provides the basis for the probable action of plant latex proteases to stop bleeding and effect wound healing as exploited in folk medicine ${ }^{24}$.

\subsubsection{Anti-Inflammatory, Antinociceptive activity and Diuretic activity}

The objective of this study was to investigate the pharmacological profile of hydro-alcoholic extract of Wrightia tinctoria (Roxb.) R.Br. Linn., (family - Apocynaceae) in mice and rats using various models. The effects of the extracts were observed in three different dose levels 300, 500 and $1000 \mathrm{mg} / \mathrm{kg}$ as extract does not show any sign a of toxicity upto $3000 \mathrm{mg} / \mathrm{dose}$. Investigations were carried out against thermal, chemical and mechanical noxious stimuli to study antinociceptive activity and on pentobarbitone induce hypnosis. Carrageenan - induced paw edema and cotton pellet induced granuloma model were employed to test anti - inflammatory activity. The parameters taken for diuretic activity were urine volume and renal excretion of $\mathrm{Na}^{+}, \mathrm{CC}^{-}$and $\mathrm{K}^{+}$ions.

Study revealed moderate analgesic effect against thermal ( $\mathrm{P}<0.001$ to 0.01$)$ and chemical $(\mathrm{P}<0.05)$ noxious stimuli and anti- inflammatory activity $(\mathrm{P}<0.001$ to 0.01$)$ at the $1000 \mathrm{mg} / \mathrm{kg}$ dose. Extract is devoid of sedative activity. Wrightia tinctoria extract considerably increases urine volume, acting as kaliuretic ${ }^{25}$. 


\subsubsection{Antiviral activity and Cytotoxicity}

Different extracts of leaf parts of Wrightia tinctoria and fruits powder of Morinda citrifolia have been studied against replication of HIV -1 (111B) in MT-4 cells and HCV in Huh 5.2 cells. Chloroform extract of Wrightia tinctoria exhibited a maximum protection of $48 \%$ against the cytopathic effect of HIV -1 (IIIB) in MT-4 cells. Fruit juice of Morinda citrifolia exhibited a displayed marked cytotoxic activity in lymphocyte (MT-4) cells (CC $50: 0.19 \mathrm{mg} / \mathrm{ml}$ ). The 50\% effective concentration for inhibition of HCV subgenomic replicon replication in Huh-5-2 cells by Morinda citrifolia was $0.98 \mu \mathrm{g} / \mathrm{ml}$ and by chloroform extract of Wrightia tinctoria was $10 \mu \mathrm{g} / \mathrm{ml}$. The concentration that reduced the growth of exponentially proliferating Huh - 5-2 cells by 50\% was greated than $50 \mu \mathrm{g} / \mathrm{ml}^{26}$.

Similarly Satyanarayana et al. and his colleagues investigated preliminary phytochemical analysis and characterization by various instrumental techniques for isatin, induribine, tryphanthrine and fatty acid. Also methanolic extract of leaf of Wrightia tinctoria have been studied against antiviral and cytotoxic activity. Methanolic extract of leaf parts of Wrightia tinctoria (WT) have been studied against replication of $\mathrm{HCV}$ in Huh 5.2 cells. The 50\% effective concentration for inhibition of $\mathrm{HCV}$ in RNA subgenomic replicon replication in huh 5-2 cells (luciferase assay) by CWT was found to be $15<\mathrm{g} / \mathrm{mL}$. The concentration that reduced the growth of exponentially proliferating Huh $5-2$ cells by $50 \%$ was greater than $50<\mathrm{g} / \mathrm{mL}^{27}$.

Also Ramalakshmi et al., investigated the total phenols, flavonoids, carotenoids, antioxidant activity, antimicrobial and cytotoxic activity of Wrightia tinctoria flower extract. Methods: Total phenols, flavonoids, carotenoides content, DPPH scavenging activity, the reducing power activity, phosphomolybednum activity, metal chelating activity, Hydrogen peroxide radical scavenging activity of crude extract, Cytotoxicity activity, GC-MS analysis and Antibacterial screening were evaluated.

Total phenols, flavonoids, carotenoides in the extract was found to be $55.29 \pm 0.45 \mathrm{mg}$ GAE, $370.53 \pm 1.213 \mathrm{mg} \mathrm{QE}$ and $1.825 \pm 0.321 \mathrm{mg} / \mathrm{g}$ respectively, where the reducing power, phosphomolybednum activity and metal chelating activity were increasing with increasing concentration of the flower extract. The antioxidant activity (IC50) of the flower extract was said to be $43.16 \mu \mathrm{g} / \mathrm{mL}$ by 2, 2-Diphenyl-1-Picrylhydrazyl method and $124.07 \mathrm{mg}$ AAE/100g of plant extract by phosphomolybednum method. The antibacterial studies of the ethanolic flower extract tested at different concentration of extracts, where $250 \mathrm{mg} / \mathrm{mL}$ concentration of extract showed good inhibitory activity against all the test pathogens compared with standard antibiotics like streptomycin and penicillin. The cytotoxic activity of flower extract was evaluated by brine shrimp lethality bioassay method and the LC50 value found to be $3.544 \mathrm{mg} / \mathrm{mL}$.

The presence of major bioactive compound, hexadecanoic acid justifies the use of the whole plant for various ailments by traditional practitioners. Further studies are needed to explore the potential phenolics, flavonoid compounds from W. tinctoria for application in drug delivery, nutritional or pharmaceutical fields ${ }^{28}$.

\subsubsection{Anti-ulcer activity:}

The purpose of the study was aimed at evaluating the antiulcer activity on leaves of Wrightia tinctoria (Roxb.) R. Br. (Family Apocynaceae) on albino rat. 
The antiulcer activity of the Wrightia tinctoria methanolic extract (TM) and Wrightia tinctoria 70\% ethanolic extract (T70E) were compared with Carboxy Methyl Cellulose (CMC), Pylorus control, Aspirin and Standard Famotidine which was evaluated by employing aspirin plus pylorus ligation induced ulcer mode. The biochemical parameters like volume of gastric juice secretion, $\mathrm{pH}$, free acidity, total acidity, ulcer index and percentage inhibition were studied at the concentration of 200 $\mathrm{mg} / \mathrm{kg}$ body weight. The plant methanolic extract showed significant gastro protective activity of $65.89 \%$. When compared with the standard drug famotidine $(20 \mathrm{mg} / \mathrm{kg})$ which showed $75.34 \%$. The result suggested that the methanolic extract of Wrightia tinctoria leaves possess anti-ulcer effect. The observed effect may be due to the presence of bioactive constituents ${ }^{29}$.

\subsubsection{Anti-diabetic activity}

The investigation has been carried out to evaluate the effect of the different extracts of the leaves of Wrightia tinctoria on alloxan induced diabetic rats of wistar strain. The experiment was carried out using six groups of albino rats. Chloroform extract showed a significant anti-diabetic activity when compared to the standard drug glibenclamide ${ }^{30}$.

\subsubsection{Antimicrobial activity}

The dried leaves of Wrightia tinctoria R.BR were subjected to successive extraction using the solvents methanol and water. The prepared extracts were then subjected to preliminary phytochemical analysis. It was found that the plant possesses steroids, alkaloids, carbohydrates, flavonoids, tannins and phenols, saponins and proteins in varying concentration. The methanol and aqueous extracts were selected for further study. They were tested against six bacteria; three Grampositive bacteria (Staphylococcus aureus, Staphylococcus pyogenes and Leuconostoc lactis) and three Gram - negative bacteria (Escherichia coli, Pseudomonas aeruginosa and Salmonella typhi) and against four Fungi (Aspergillus niger, Aspergillus flavus, Rhizopus indicus and Mucor indicus). For antimicrobial test, well diffusion technique was used and the zone of inhibition of microorganisms was measured in $\mathrm{mm}$. the pattern of inhibition varied with the solvent used for extraction and the microorganism tested. Among these extracts aqueous extract showed significant antibacterial activity against most of these bacteria but in case of fungus against methanol extract showed some result. The most susceptible microorganism was Leuconostoc lactis (32 mm) followed by Pseudomonas aeruginosa (31 mm zone of inhibition in aqueous extract) and Mucor indicus (32 mm zone of inhibition in methanol extract) ${ }^{31}$.

Similarly Vijayaragavan Thangaraj studied ${ }^{31}$ Pharmacognostical and antimicrobial studies on the leaf of Wrightia tinctoria, Br., belongs to the Family of Apocynaceae. The plant is commonly known as vey Wrightia tinctoria pale in Tamil Language, in Telugu: ankuduchettu, chiti-anikudu, kondajemudu and Indrajau in Hindi Language. It has been used for many diseases and disorders. Particularly the Wrightia tinctoria, Br., Bark is used for anti dysenteric, Flatulence, bilious affection dropsy and the leaves has been using for relieving toothache, and proteolytic activity. But there is little evidence of leaf on Antimicrobial studies. In present study we have attempt was made to study its pharmacognostical features including Macroscopic, Microscopic Features, Physio-Chemical parameters and Phyto chemical studies, little extensive of Anti-Microbial studies. The study on pharmacognostical characters and Anti microbial activities of Wrightia tinctoria, Br., leaf has given useful information in regard to its correct identity and help to differentiate from the closely related other species of Wrightia ${ }^{32}$. 
Vedhanarayanan et al., investigated ${ }^{32}$, the antibacterial activity of different extracts (Chloroform, ethanol and methanol) of Wrightia tinctoria against the human pathogenic bacterial strains, Escherichia coli, Bacillus subtilis, Staphylococcus aureus and Pseudomonas aeruginosa by disc diffusion method on agar. The findings showed potential antibacterial properties of the extracts against the organisms tested. Among the three solvents tested, ethanol extract of leaf showed higher inhibition zone. Ethanol extract of Wrightia tinctoria exhibits maximum zone of inhibition against Escherichia coli $(29 \mathrm{~mm})$, Bacillus subtilis $(24 \mathrm{~mm})$ Staphylococcus aureus $(30 \mathrm{~mm})$ and Pseudomonas aeruginosa $(24 \mathrm{~mm})$.

Preliminary phytochemical analysis of Wrightia tinctoria showed the presence of alkaloids, flavonoids, phenols, saponins, steroids and tannins ${ }^{33}$. Lakshmi Devi etal (2009) ${ }^{34}$ investigated the antibacterial activity of different extracts of Wrightia tinctoria (Roxb.) R.Br., against three Gram positive bacteria, viz.Staphylococcus aureus, Bacillus subtilis and Staphylococcus epidermidis and two Gram negative bacteria viz. Escherichia coli and Pseudomonas aeruginosa. Methanolic extract showed antibacterial activity only against Gram positive bacteria, which was less than that of the standard drug Ciprofloxacin ${ }^{35}$.

\subsubsection{Immunomodulatory Activity}

Wrightia tinctoria (Roxb.) R.Br. (WT) has been reported to exhibit number of therapeutic uses such as astringent, stomachic, febrifuge, skin diseases and tonic in India. The objective of the present study was to investigate the immunomodulatory activity of the bark extracts of WT using delayed type hypersensitivity reaction and carbon clearance assay. Powdered dried barks of WT were extracted with petroleum ether $60-80^{\circ} \mathrm{C}$ (PEWT), alcohol (ALWT) and aqueous alcohol (AQWT) $(60 \%$ water $+40 \%$ ethanol) successively. PEWT and ALWT extracts $(200,400 \mathrm{mg} / \mathrm{kg}$, p.o $)$ produced a significant increase in delayed type hypersensitivity in response to sheep red blood cells (SRBC). PEWT showed better activity than ALWT in delayed type hypersensitivity response. ALWT (200 and 400mg/kg, p.o) in dose dependent manner have shown significantly increase in the phagocytic activity. The above results reveal that ALWT possesses immunostimulant activity in carbon clearance assay whereas PEWT and ALWT showed Immunomodulatory activity in delayed type hypersensitivity model ${ }^{35}$.

\subsubsection{Diuretic activity}

Water and alcoholic extract of leaves of Wrightia tinctoria (Apocynaceae) were subjected to various phytochemical analysis to identify carbohydrates, phytosterols, tannins and lignin. Both the extracts were investigated for diuretic activity. Total urine volume and the concentration of sodium, potassium and chloride ions in the urine those Parameters are taken into account during the experimental work on each rat. The extracts showed a potent diuretic effect with increase in electrolyte concentration in urine, when compared with standard drug (frusemide) in albino rats ${ }^{36}$.

\section{CONCLUSION}

The main constituents present in Wrightia tinctoria are triterpenoids namely lupeol and lupenone. Flavonoids quercetin and rutin mostly from flowers. A terpene known as Wrightial from immature pods. Sterols $14 \alpha$-methyl zymosterol and desmosterol from seeds. 
Wrightia tinctoria possess multiple pharmacological activities such as Wound healing, Antiinflammatory, Antipsoriatic, Postcoital interceptive, Antinoceptive, Parakeratosis, Antipityrosporum, Antidandruff, Antioxidant, Clot inducing, Diuretic, Antiviral, Cytotoxicity and Antiulcer activity. The studies thus substantiate the traditional use of the plant Wrightia tinctoria in treatment of liver disorders. Specially the triterpenoids deserves detailed preclinical evaluation in order substantiate its therapeutic potential and mechanism of action.

\section{ACKNOWLEDGEMENT}

The authors are thankful to Dr.T.K.Ravi, Principal, College of Pharmacy, Sri Ramakrishna Institute of Paramedical Sciences, Coimbatore, Tamilnadu for his encouragement and support.

\section{REFERENCES}

1. Kirtikar KP and Basu, B.D.; Indian Medical Plants, 2nd ed., International Book Distributors, Dehradun. 1981, 15811583.

2. Asima Chatterjee, Satyesh and Chandra Pakrashi. The Treatise of Indian Medicinal Plant, Vol. 4, National Institute of Science and Communication and Information Resources, New Delhi, 2003, 125 - 127.

3. Lakshmi Devi S and Madhu C Divakar. Pharmacognostical Evaluation on the leaves of Wrightia tinctoria (Roxb) R.Br. Hygeia J D Med. 2012; 4(1):104-111.

4. Nadkarni AK. The Indian Materia Medica revised and enlarged edition, Vol. 1, Popular Prakashan, Bombay, 1954, $1296-1297$.

5. Mahendra S, Khyadel Nityanand P, Vaikas. Pharmacognostical and physiochemical standardization of leaves of Wrightia tinctoria (Roxb.) R. Br. Int. J. of Pharma Res and Develop. 2009; Vol. 8 (5):1-10.

6. Ramchandra P, Basheermiya M, Krupadanam GLD, Srimannarayana G. Wrightial, a new terpene from Wrightia tinctoria . J. Nat. Prod.1993; Vol.5 (10): 11811-1812.

7. Sethi PD. Separation of alkaloidal constituents of Wrightia tinctoria by TLC. Planta Med.1970; 18 (1): 20-29.

8. Rao MN, Rao EV, Rao VS. Occurrence of oleanolic acid in the pods of Wrightia tinctoria Br. Cur. Sci.1968; 37 (22):645.

9. Tomar R, Kumar R, Jagannadhan MV. A stable serine protease, Wrightia, from the latex of the plant Wrightia tinctoria (Roxb.) R. Br., Purification and biochemical properties. J Agric Food Chem.2008; 56 (4): 1479-1487.

10. Jain PS, Bari SB. Isolation of Lupeol, Stigmasterol and Campesterol from petroleum ether extract of woody stem of Wrightia tinctoria. Asian J Plant Sci.2010; 9 (3):163-167.

11. Khyade MS, Vaikos NP. Comparative Phytochemical and Antibacterial Studies on the bark of Wrightia tinctoria and Wrightia arborea. Int J Pharm Bio Sci.2011; 2(1): 176-181.

12. Rajani, Srivastava. A review on phytochemical, pharmacological, and pharmacognostical profile of Wrightia tinctoria: Adulterant of kurchi. Pharmacog review.2014; 8(15):36-44.

13. Bharani M, Thirunethiran Karpagam1, Varalakshmi B, Gayathiri G, Lakshmi Priya K. Synthesis and Characterization of Silver Nano Particles From Wrightia tinctoria. Int J App Bio Pharm Tech. 2012; 3(1):58-63.

14. Divakar MC, Lakshmi Devi S. Wound healing activity of the leaves of Wrightia tinctoria (Roxb.) R. Br. Indian Drugs. 2012; 49(3):40-46.

15. Veerapur VP, Palkar MB, Srinivasa H, Kumar MS, Srinivasan KK. The effect of ethanol extract of Wrightia tinctoria bark on wound healing in rats. J Nat Rem.2004; 4 (2):155 - 159.

16. Keshri G, Kumar S, Kulshrestha DK, Rajendran SM, Singh MM. Postcoital interceptive activity of Wrightia tinctoria in Sprague- Dawley rats: a preliminary study. Contraception. 2008; 78 (3):266- 270.

17. Reddy YSR, Venkatesh S, Ravichandran T, Murugan V, Suresh B. Antinociceptive activity of Wrightia tinctoria bark. Fiftoterapia, 2002; 73 (5):421- 423.

18. Mitra SK, Seshadri SJ, Venkatarayana MV, Gopumadhavan S, Reversal of Parakeratosis, A feature of psoriasis by Wrightia tinctoria (In Emulsion) Histological Evaluation based on mouse tail test. Indian J Dermatol. 1998; 43 (3):102-104. 
19. Krishnamoorthy JR, Ranganathan S. Anti pityrosporum oval activity of a herbal drug combination of Wrightia tinctoria R. Br. and Hibiscus rosasinensis ; Indian J Dermatol. 2000; 45 (3):125-126.

20. Krishnamoorthy JR, Ranganathan S, Gokul Shankar S, Ranjith S. Dano A. Herbal solution for Dandruf. Afr J Biotec.2006; 5 (10):960-962.

21. Dhanabal SP, Baskar Anand Raj, Muruganatham N, Praveen TK, Raghu PS. Screening of Wrightia tinctoria leaves for Anti Psoriatic activity. Hygeia J D Med.2012; 4 (1):73-78.

22. Baktha Reddy NB. Evaluation of the effect of Wrightia tinctoria formulation (Reg. SO $\mathrm{R}^{\circledR}$ ) on Psoriasis Vulgaris, US Termatol Rev. 2007, 6-8.

23. Rajesh R, Shivaprasad HV, Gowda CD, Nataraju A, Dhananjaya BL, Vishwanath BS. Comparative study on plant latex protease and their involvement in hemostatis : a special emphasis on clot inducing and dissolving properties. Planta Med. 2007; 73(10):1061 - 1067.

24. Bigoniya P, Shukla A, Agrawal GP, Rana AC. Pharmacological Screening of Wrightia tinctoria bark hydro alcoholic extracts. Asian J Exp Sci. 2008; 22 (3): 235 - 244.

25. Selvam P, Murugesh N, Witvrouw M, Keyaerts E, Neyts J. Studies of Antiviral activity and cytotoxicity of Wrightia tinctoria and Morinda citrifolia. Indian J Pharm Sci. 2009; 71 (6):670-672.

26. Satyanarayana S, Selvam P, Asha J, Rijo MG, Revikumar KG, Neyts J. Preliminary phytochemical screening and study of Antiviral activity and Cytotoxicity of Wrightia tinctoria. Int J Chem Sci. 2009; 7 (1):1-5.

27. Ramalakshmi S, Edaydulla N, Ramesh P, Muthuchelian K.. Investigation on cytotoxic, antioxidant, antimicrobial and volatile profile of Wrightia tinctoria (Roxb.) R. Br. flower used in Indian medicine. Asi Pas J Tro Dis. 2012, D68-S75.

28. Madhu C Divakar, Lakshmi Devi S. Antiulcer activity of Wrightia tinctoria (Roxb.) R. Br. Der Pharmacia Sinica. 2011; 2(2):355-350.

29. Shruthi A, Latha KP, Vagdevi HM, Pushpa Band Shwetha C. Anti-diabetic activity of the leaves extracts of Wrightia Tinctoria on alloxan induced diabetic rats. J Chem Pharm Res. 2012; 4(6):3125-3128.

30. Sridhar S, Kamalakannan P, Elamathi R, Deepa T, Kavitha R. Studies on antimicrobial avtivity, physio-chemical and phytochemical analysis of Wrightia tinctoria. Int J Pharm Res Dev. 2011; 3 (8):139-144.

31. Vijayaragavan thangaraj. Pharmacognostical and anti microbial studies on the leaf of Wrightia tinctoria Br. Int $J$ Pharm Tech. 2013; 5(1):5326-5336.

32. Vedhanarayanan P, Unnikannan P, Sundaramoorthy P. Antimicrobial activity and Phytochemical Screening of Wrightia tinctoria (Roxb.) R.br. J Pharmacog Phytochem. 2013; 2(4):123-125.

33. Patricia Thabah, Murugananthan G, Naresh Chandra Joshi, Nandakumar K, Lakshman K, Sahil Talwar. Immunomodulatory Activities of Wrightia Tinctoria (Roxb.) R. Br Bark Extracts. Pharmacologyonline 2009; 3: 663-669.

34. Lakshmi Devi S, Madhu C Divakar. Antibacterial activity on Wrightia tinctoria (Roxb) R.Br. Leaf extract. Druglines. 2008-2009; 11(1\&2): 17-20.

35. Sathianarayanan S, Asha Jose, Rajasekaran A, Rijo Mary George, Amrutha BC. Diuretic activity of aqueous and alcoholic Extracts of Wrightia tinctoria. Int J Phyto Pharmacology. 2011; 2(1):7-8. 